universally available as it has been shown to reduce psychological morbidity in high risk groups. ${ }^{4}$

Most departments did not know how a relative finds out the result of a necropsy, although this will usually be available from the coroner's officer. It is important that all relatives should have confirmation of the cause of death. Few do, and it is the responsibility of the accident and emergency staff to ensure that this information is communicated to the family either directly or through their general practitioner. In a time of stress relatives may not be able to absorb much oral information. All bereaved relatives should be given written information as well as oral instructions. There are many advice sheets available from national organisations, as well as leaflets produced by individual hospitals. The leaflets sent out by accident and emergency departments were often incomplete (table II).

\section{IMPROVING CARE}

Staff in accident and emergency departments appreciate the severe psychological trauma caused by a cot death. Paediatricians, health visitors, and counsellors are often brought in at an early stage. The body is treated as a loved one rather than an inanimate object, as sometimes occurs with adults, and a photograph is often taken as a final lasting memory. Most departments give parents one of the nationally produced leaflets to help them cope with their bereavement. Should not this level of care be extended to the relatives of all patients dying in accident and emergency departments? The death of an adult is just as traumatic as the death of a child; the sense of loss is just as great.

Most departments commented on the inadequacy felt by staff when dealing with death, grief, and bereavement. Extra training was widely requested; nurses have in house training at many centres, but it is rare for doctors. One third of deaths in hospital occurred within a few hours of arrival in hospital. ${ }^{3}$ All accident and emergency staff should therefore have adequate training in the care of the suddenly bereaved with emphasis placed on communication and counselling skills.

Accident and emergency departments should review the facilities available for the care of bereaved relatives and there should be an agreed policy to ensure optimal treatment of the family. This must include sufficient flexibility to accommodate the variable wishes of the families. Management of bereavement is one of the most difficult and delicate tasks performed in the accident and emergency department. The last memory is the lasting memory. With appropriate facilities, staff, follow up, and training long term morbidity in the family may be prevented and staff will derive more satisfaction from their care.

\footnotetext{
1 McClauchlan CAJ. Handling distressed relatives and breaking bad news. $B M \mathcal{J}$ 1990;301:1145-7.

2 Tachakra SS, Beckett MW. Dealing with death in the accident and emergency department. Brf Accid Emerg Med 1986;1:10-1.

3 Yates DW, Ellison G, McGuiness S. Care of the suddenly bereaved. BMF 1990;301:29-31.

4 Raphael B. Preventative intervention with recently bereaved. Arch Gen Psychiatry 1977;34:1450-4.
}

(Accepted 28 February 1992)

\section{Department of \\ Histopatholoy, Bristol \\ Royal Infirmary, Bristol BS2 8HW \\ Lynn Hirschowitz, senior registrar in histopathology}

Departments of Public Health Medicine and Cytology, Southmead Hospital, Bristol BS10 5NB Angela E Raffle, consultant in public health medicine

Elizabeth F D Mackenzie, consultant cytopathologist

Department of

Epidemiology, Bristol

Medical School, Bristol

BS8 2PR

A O Hughes, senior lecturer in medical statistics

Correspondence to: Dr L Hirschowitz, Bristol Maternity Hospital, Bristol BS2 8EG.

BMf 1992;304:1209-12

\title{
Long term follow up of women with borderline cervical smear test results: effects of age and viral infection on progression to high grade dyskaryosis
}

\author{
Lynn Hirschowitz, Angela E Raffle, Elizabeth F D Mackenzie, A O Hughes
}

\section{Abstract}

Objective-To follow up and assess the significance of borderline change in cervical smears.

Design-Retrospective study of women undergoing routine cervical cytological screening in 1981 .

Setting-Avon Cervical Screening Programme, covering 250000 women in Bristol and Weston super Mare.

Subjects -437 women showing borderline cervical changes in 1981 and 437 age matched controls with normal results in 1981 .

Main outcome measures-Cytological progression to high grade dyskaryosis (cervical intraepithelial neoplasia grade III or invasive carcinoma).

Results-During follow up ranging from 13 to 106 months 98 of the 437 women $(22.4 \%)$ with borderline cytological changes on routine cervical cytology screening had a subsequent smear test showing high grade dyskaryosis compared with three of the 437 women $(0.9 \%)$ in the control group. The risk of progression was greater in women aged 20 to 39 than in those aged 40 and over. Human papillomavirus infection had initially been diagnosed cytologically in 101 of the $437(23 \%)$ women with borderline results. Significantly fewer of these women developed high grade dyskaryosis (13/98 $(13 \%) v 88 / 339(26 \%), \mathrm{p}<0.05)$.

Conclusions-Women with borderline smear test results are at increased risk of developing high grade dyskaryosis, particularly if the borderline changes occur without cytological features of human papil- lomavirus infection. Progression occurs within three years in $\mathbf{5 0 \%}$ of cases, although a linearly increasing risk was sustained over the nine years of follow up and was greatest in women aged 20 to 39. Careful follow up of these women is indicated.

\section{Introduction}

Cytological criteria for diagnosing mild, moderate, or severe dyskaryosis in ceryical smears are well established.' In some cases, however, smears show only minor nuclear abnormalities that could reflect either the effects of inflammation or the potential for neoplastic growth, and these two possibilities cannot be distinguished cytologically. The British Society for Clinical Cytologists recommended that the term borderline be used to describe such smears.

Data from the Avon Cervical Screening Programme have shown a steady annual increase in the number of women whose cervical smears are designated as borderline. In 1981, the first year this result was separately classified in the programme's records, 638 women $(1.5 \%$ of all of those assessed) were diagnosed as having borderline cytological changes. The number of women with borderline results has risen steadily, both in absolute numbers and as a proportion of all smears examined. In 1988 and $1989,4 \cdot 8 \%$ and $4 \cdot 2 \%$ of the women tested had borderline results, and their numbers in both years exceeded 2000 , more than the combined total of women with dyskaryotic smears of all grades. 
The Avon Cervical Screening Programme has defined protocols for reporting all categories of abnormal smears and for subsequent patient management. In keeping with these protocols, a great deal of time is spent not only on the initial diagnosis but also on the follow up of women with this type of smear. After a cytoscreener has made a presumptive diagnosis of borderline change, the cervical smear is then re-examined (double screened) by a senior medical laboratory scientific officer to confirm this finding. Until 1988 all borderline smears were subsequently scrutinised by a member of the medical staff (triple screened) before a final report was issued to the referring clinician or general practitioner. The programme's policy is to request a follow up smear test from all of these women at six months and from those aged 35 years or over a further test 12 months later. The follow up smears are again double screened. If a persistent or progressive abnormality is detected the women are referred for colposcopic examination.

If the work generated by the follow up of women with all categories of abnormal smears continues to increase, by 1993 about half of the existing laboratory capacity in Avon will be devoted to follow up work alone. $^{2}$ This diversion of resources has important financial implications for the routine cervical screening programme.

Although data are available on the prognostic implications of dyskaryotic smears, little is known about the significance of borderline smears, and the existing policies for monitoring women with borderline results are, of necessity, arbitrary. We assessed both the significance and the long term prognosis for women with borderline results, with a view to establishing follow up policies that make best use of laboratory time and resources.

\section{Methods}

The Avon Cervical Screening Programme serves a catchment population of about 250000 women aged 20 to 64 years who undergo five yearly cervical screening. The proportion of the population in social classes I, II, and III is slightly higher than in England as a whole. Ninety per cent of the smears are examined at Southmead Hospital's cytology laboratory and $10 \%$ at the Bristol Maternity Hospital. MUMPS software is used to store the results on a DEC Microvax computer.

The records of all women whose cervical smears had been reported as showing borderline changes on cervical screening in 1981 were retrieved from the programme's computer database. Of these 638 women, 201 were excluded from the study because of earlier dyskaryotic smears or follow up for a period of less than one year. Most women in the latter category had moved away from the area. Smear histories of the remaining 437 women, aged from 15-72 years, were retrieved up to and including December 1989. From the programme database we also retrieved the records of an age

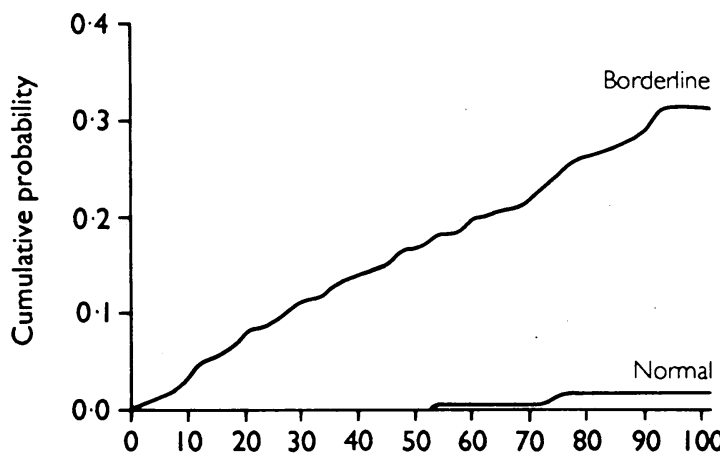

of progression to high grade dyskaryosis in patients with borderline and normal smear test results as assessed by Kaplan-Meier life tble analysis matched control group of 437 women who, in 1981, had had a normal smear test result, who had had no previous abnormal smear test results, and whose birth dates were closest to those of their counterparts with borderline results. The following data were examined: (a) the age distribution of women with borderline smear test results; $(b)$ the duration of follow up in borderline and control groups; $(c)$ the numbers of women in the borderline and control groups who had subsequent smear tests showing either low grade dyskaryosis (mild or moderate dyskaryosis, cervical intraepithelial neoplasia grade I or II) or high grade dyskaryosis (severe dyskaryosis, cervical intraepithelial neoplasia grade III, or invasive carcinoma) on cytological examination; $(d)$ the numbers of women in both groups showing evidence of infection (viral, fungal, or protozoal) in the initial cervical smear test; (e) the relation between cytological evidence of viral infection and progression to high grade dyskaryosis in both groups of women; $(f)$ the interval between the initial borderline result and a smear test showing high grade dyskaryosis.

The histological diagnoses in biopsy material, when available, were compared with the cytological findings.

The censuring of the follow up period indicated that progression to high grade dyskaryosis would need to be assessed by Kaplan-Meier life table techniques and comparisons made by the log rank test. Other factors were compared by $\chi^{2}$ analysis after small numbers were eliminated by combining appropriate groups.

\section{Results}

The age specific distribution of borderline test results was highest between 20 and 29 years. After application of the above exclusion criteria, the numbers in the groups aged 20-24 and 25-29 were 82 and 80 respectively. The duration of follow up of the women with borderline changes ranged from 13 to 106 months (mean 73 (SD 23), median 79). In the control group the follow up period ranged from 13 to 105 months (mean 68 (19), median 65).

In the borderline group there was progression to high grade dyskaryosis in 98 women (22.4\%), 90 being aged under 40 (table I). The highest crude rate of progression, 29 out of 80 women (36.3\%), occurred in women aged 25-29. Only three of the 437 women in the control group progressed to high grade dyskaryosis, their ages being 23, 26, and 29 in 1981 .

The time taken to progress to high grade dyskaryosis ranged from three to 94 months. The life table corrected progression rate in the women with borderline results is compared in figure 1 with that for the age matched controls. In figure 2 the progression rate in the women with borderline results is classified into age groups. The log rank test confirmed a significant difference between the progression of disease in women with borderline results and that in women with normal results $(p<0.001)$. In addition, age significantly affected progression in women with borderline results: those over $\mathbf{4 0}$ had a significantly lower rate of progression $(p<0.001)$. than had the women aged between 20 and 39 (fig 2). In $50 \%$ of the women who had developed high grade dyskaryosis within the follow up period, progression had occurred during the first 34 months, but in some the delay was almost eight years, with interim smear test results either classified as normal (roughly a third) or showing low grade dyskaryosis (roughly two thirds). Normal results occurring after the initial borderline change were double screened in the same manner as abnormal smears - that is, by a cytoscreener and a medical laboratory scientific officer-and are therefore considered to be true normal results.

At the time of the initial borderline result 10 women 
TABLE II - Proportions of patients with borderline results whose initial smears showed cytological evidence of human papillomavirus infection

\begin{tabular}{lc}
\hline $\begin{array}{l}\text { Age } \\
\text { (years) }\end{array}$ & Proportion \\
\hline$<20$ & $19 / 37$ \\
$20-24$ & $29 / 82$ \\
$25-29$ & $13 / 80$ \\
$30-34$ & $14 / 67$ \\
$35-39$ & $12 / 64$ \\
$40-44$ & $4 / 45$ \\
$45-49$ & $7 / 26$ \\
$50-54$ & $2 / 25$ \\
$55-59$ & $1 / 7$ \\
$60-64$ & $0 / 2$ \\
$\geqslant 65$ & $0 / 2$ \\
\hline
\end{tabular}

had evidence of candida and seven of trichomonas infection. The two organisms were confined to women under 59. Cytological evidence of human papillomavirus infection was noted in a further 101 of these women and was particularly common in women under $20(19 / 37)$ and in those aged 20-24 (29/82) (table II). The association of human papillomavirus infection with age (considering all women of 50 and over as one age group) was significant $\left(\chi^{2}=36 \cdot 3, \mathrm{df}=7, \mathrm{p}<0 \cdot 0001\right)$. There was no cytological evidence of human papillomavirus infection in any of the normal smears of the 437 women used as controls. In the borderline group only 13 of the 98 women who subsequently developed high grade dyskaryosis $(13 \cdot 3 \%)$ had had a cytological diagnosis of human papillomavirus infection at the time of the initial smear test. In contrast, 88 of the 339 women in this group who did not develop high grade dyskaryosis $(26.0 \%)$ had been diagnosed as having human papillomavirus infection $\left(\chi^{2}=6 \cdot 2\right.$, $\mathrm{df}=1, \mathrm{p}<0 \cdot 05$ ).

Material for histological examination was available from 88 of the 98 women in whom disease progressed to high grade dyskaryosis. Histological examination of the biopsy material in 12 of them showed no abnormality or only mild dyskaryosis (cervical intraepithelial neoplasia grade I) despite the high grade smear result, giving a false positive rate of $12 \cdot 2 \%$. Of the remaining 76 biopsy specimens, 69 showed histological changes of cervical intraepithelial neoplasia grade II or III and seven microinvasive carcinoma. Two of the patients with microinvasive carcinoma were aged 20-24, two were $25-29$, and three were $35-39$. Only one of the patients with microinvasive carcinoma had had cytological evidence of human papillomavirus infection.

A further 23 of the 339 patients with borderline smear test results who did not show progression to high grade dyskaryosis had colposcopy and biopsy. Eleven had significant histological abnormalities. Three of these patients, who had been referred for further examination because of clinical symptoms or an abnormal macroscopic appearance of the cervix, were found to have invasive carcinoma. Two of the carcinomas were squamous (affecting women of 32 and 37) and the third carcinoma, in a woman aged 28 , was adenosquamous. The other eight patients had histological changes of cervical intraepithelial neoplasia grade III. The lowest possible estimate of the false negative rate was therefore $3 \cdot 2 \%(11 / 339)$. Both of the patients with squamous carcinoma had had cytological evidence of human papillomavirus infection in the initial borderline smear test.

\section{Discussion}

Our results indicate that just over one in every five women $(22 \cdot 4 \%)$ presenting with borderline cervical smear cytology in Avon during 1981 subsequently developed high grade dyskaryosis within the nine year follow up period. The risk of progression was greatest in young women (under 39), particularly those in whom the borderline change was not associated with cytological evidence of papillomavirus infection.

Comparison of these findings with those of earlier studies is limited by differences in terminology, in patient selection and treatment, in the duration of follow up, and in the method used to establish the end point diagnosis - histology or cytology. ${ }^{3.5}$ Hulka, in a follow up study of 359 patients who had atypical smear test results on initial screening, found that in situ carcinoma (cervical intraepithelial neoplasia grade III) developed in $3 \cdot 1 \%$ and invasive carcinoma, confirmed histologically, in $4.5 \% .^{6}$ In most cases the disease progressed within 18 months, but in one or two cases progression occurred after more than two years. On the basis of computer projections, obtained from a much

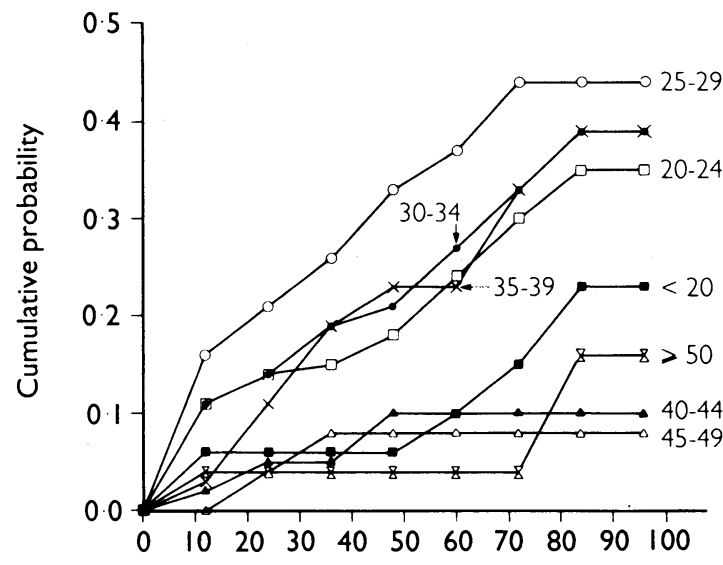

Time since initial smear (months)

FIG 2-Probability of progression to high grade dyskaryosis according to age group

more limited follow up study, Richart and Barron predicted that the median progression time (the time taken for disease to progress in half of the women in the study) from all grades of dyskaryosis to carcinoma in situ was 44 months. ${ }^{3}$ The predicted median progression time in women with very mild dysplasia (which, of the categories used in that study, probably corresponds most closely to borderline change) was 86 months. In contrast, our follow up time was longer than 86 months and fewer than $25 \%$ of women with borderline smear test results developed cervical intraepithelial neoplasia grade III or carcinoma.

Nyirjesy studied a group of 434 women with atypical (so called class 2 ) results. ${ }^{4}$ Of 57 patients who had a cone biopsy after persistently atypical smear test results, $16(28 \cdot 1 \%)$ were found to have developed carcinoma in situ or invasive squamous carcinoma. Davis et al found that $31 \cdot 2 \%$ of women who underwent a cone biopsy for persistently atypical smear test results had histological evidence of cervical intraepithelial neoplasia grade III or of a more advanced lesion. ${ }^{7}$ Similar results were obtained by Soutter et al, who showed that 13 of the 44 women (29.5\%) referred for colposcopically directed biopsies because of smears that contained mildly atypical cells (not amounting to dyskaryosis) had developed cervical intraepithelial neoplasia grade III or invasive carcinoma.$^{8}$ It is not clear over what period of time this progression took place. More recently, Jenkins and Tay reported the histological diagnosis of cervical intraepithelial neoplasia grade III in $25 \%$ of women whose smears had shown borderline dyskaryosis. ${ }^{9}$

More information is available about the progression of cervical neoplasia in women with cervical intraepithelial neoplasia grade I. Campion et al observed that in 26 of the 100 women studied disease progressed to cervical intraepithelial neoplasia grade III over a 19 to 30 month follow up period. ${ }^{10}$ Robertson et al studied the progression rate of cervical intraepithelial neoplasia grade I in a group of 1781 women. ${ }^{11}$ In all, 434 were lost to follow up. In $26 \%$ of the remaining 1347 women there was progression to a more severe lesion. Invasive carcinoma was confirmed in 10 patients and cervical intraepithelial neoplasia grade III in 201 (15\%). Neither in this study nor in that of Giles $e t a l^{12}$ was there a significant relation between age and the likelihood of disease progression. Over an average follow up period of 50 months Nasiell et al found that disease progressed to a more severe lesion in $30 \%$ of 894 women with moderate dyskaryosis (cervical intraepithelial neoplasia grade II). ${ }^{13}$ The comparatively slow progression of dyskaryosis in women with borderline smears is consistent with the hypothesis that the rate of progression is related to the degree of dyskaryosis. 
In a prospective study of 100 women with cervical intraepithelial neoplasia grade I, $39 \%$ were found to have human papillomavirus infection by filter DNA hybridisation. ${ }^{10}$ In 22 of the $26(85 \%)$ who developed progressive disease human papillomavirus type 16 DNA was detected. Mitchell et al calculated that the risk of developing cervical intraepithelial neoplasia grade III was increased $15 \cdot 6$-fold in women with cytological evidence of human papillomavirus infection and $38 \cdot 7$-fold if the women were under $25 .{ }^{14}$ The risk factor was calculated by comparing the number of carcinomas that developed in women with papillomavirus infection with the expected number of cervical cancers in the general population. The expected incidence figures for the general population were obtained from the South Australian Central Cancer Registry. If women with borderline and those with normal smear test results are analysed together in our study 13 of the $101(12.9 \%)$ women with cytological evidence of human papillomavirus infection progressed to high grade dyskaryosis compared with 88 of the $773(11.4 \%)$ without cytological evidence of viral infection. The risk of progression therefore seems to be increased only slightly, if at all, in women with cytopathic human papillomavirus infection. Our data also show that the cytopathic effects of human papillomavirus infection are almost invariably associated with, or in some cases may be indistinguishable from, borderline cytological changes. This makes it difficult to assess the extent to which cytopathic human papillomavirus infection is an independent risk factor. The present findings suggest that progression from borderline change to high grade dyskaryosis is more likely if cytological evidence of human papillomavirus infection is absent. One possible explanation is that human papillomavirus infection may merely simulate borderline changes without conferring the risk of neoplasia.

Cytological examination alone underestimates the number of women with human papillomavirus infection. ${ }^{15}$ Nuovo et al showed that neither light microscopy nor clinical examination was of any value in predicting the presence of occult human papillomavirus infection. ${ }^{16}$ The women at risk of developing cervical carcinoma may be harbouring latent virus that is not cytologically detectable. In a recent study using the polymerase chain reaction to amplify viral DNA human papillomavirus type 16 DNA was found in $84 \%$ of cervical smears that appeared cytologically normal. ${ }^{17}$ This unexpectedly high detection rate of human papillomavirus in normal cervices has been confirmed in other studies ${ }^{18}$ and serves to emphasise that the evidence linking cervical carcinoma with human papillomaviruses is as yet inconclusive. ${ }^{19-21}$

The problem of false negative Papanicolaou smears from invasive cervical carcinomas, as occurred in three patients in the present study, is well recognised. ${ }^{1122-24}$ Cervical cytology is thought to be more effective for detecting intraepithelial than invasive carcinoma. ${ }^{11}$ In our study all of the women in whom microinvasive carcinoma was found had developed frankly dyskaryotic smears, suggesting that cytological examination may be more reliable in diagnosing microinvasive than deeply invasive carcinoma.

The management of women with borderline smear test results is controversial and entails not only financial and logistical considerations but also a compromise between causing unnecessary anxiety to a large number of women (only some of whom would otherwise develop carcinoma) and failing to detect those women in whom carcinoma could be prevented. Management policies for women with borderline smear cytology vary widely throughout the country. Evans et al recommended that patients with smears showing warty changes, borderline change, or mild dyskaryosis should have a repeat test within three months and be referred for colposcopy if the abnormality persisted. ${ }^{22}$ In their discussion of the risk of cervical neoplasia in patients with vulval warts Singer and Jenkins proposed a follow up protocol that, they suggested, would also provide a high level of protection for women with borderline results or human papillomavirus related cervical cytological changes: a repeat smear should be taken at six months and again at 12 months-if both these smears are negative the patients should be discharged to three yearly follow up..$^{21}$

Our results show that borderline change in a cervical smear confers an increased risk, sustained for several years, of progression to high grade dyskaryosis, although in most patients the progression is relatively slow. Our findings suggest that women aged 20 to 39 should be followed up particularly closely, even if one or more subsequent smear test results are negative. We think that a repeat test at three or six months is unlikely to offer much protection against a risk that is clearly a long term one. Every care should be taken to ensure that these women are not lost to follow up and our recommendation would be for annual repeat tests to be submitted for several years before reverting to routine recall.

We thank Dr B Alden for help with retrieval of Avon Cervical Screening Programme records.

1 Evans DMD, Hudson EA, Brown CL, Boddington MM, Hughes HE, Mackenzie EFD, et al. Terminology in gynaecological cytopathology: report of the Working Party of the British Society for Clinical Cytology f Clin Pathol 1986;39:933-44.

2 Raffle AE, Alden B, Mackenzie EFD. Six years' audit of laboratory workload and rates of referral for colposcopy in a cervical screening programme in three districts. $B M \mathcal{1}$ 1990;301:907-11.

3 Richart RM, Barron BA. A follow-up study of patients with cervical dysplasia. Am F Obstet Gynecol 1969;105:386-93.

4 Nyirjesy I. Atypical or suspicious cervical smears. An aggressive diagnostic approach. FAMA 1972;222:691-3.

5 Kinlen LJ, Spriggs AI. Women with positive cervical smears but without surgical intervention. A follow up study. Lancet 1978;ii:463-5.

6 Hulka BS. Cytologic and histologic outcome following an atypical cervical smear. Am J Obstet Gynecol 1968;101:190-9.

7 Davis RM, Cooke JR, Kirk RF. Cervical conisation: an experience with 400 Davis RM, Cooke JK, Kirk RF. Cervical
patients. Obstet Gynecol 1972;40:23-7.

8 Soutter WP, Wisdom S, Brough AK, Monaghan JM. Should patients with mild atypia in a cervical smear be referred for colposcopy? Br f Obstet Gynaecol 1986;93:70-4.

9 Jenkins D, Tay SK. Management of mildly abnormal smears. Lancet 1987;i:748-9.

10 Campion MJ, McCance DH, Cuzick J, Singer A. Progressive potential of mild cervical atypia: prospective cytological, colposcopic and virological study. Lancet 1986;ii:237-40.

11 Robertson JH, Woodend BE, Crozier EH, Hutchinson J. Risk of cervical cancer associated with mild dyskaryosis. BMf 1988;297:18-21.

12 Giles JA, Deery A, Crow J, Walker P. The accuracy of repeat cytology in women with mildly dyskaryotic smears. Br $\mathcal{O}$ Obstet Gynaecol 1989;96: 1967-70.

13 Nasiell K, Nasiell M, Vaclavinkova V. Behaviour of moderate cervical dysplasia during long-term follow-up. Obstet Gynecol 1983;61:609-14.

14 Mitchell H, Drake M, Medley G. Prospective evaluation of risk of cervical cancer after cytological evidence of human papilloma virus infection. Lancet $1986 ; \mathrm{i}: 573-5$

15 Kirkup W, Evans AS, Brough AK, Davis JA, O'Loughlin T, Wilkinson G, et al. Cervical intraepithelial neoplasia and warty atypia: a study of colposcopic, histological and cytological characteristics. Br f Obstet Gynaecol 1982;89:571-7.

16 Nuovo GJ, Nuovo MA, Cottral S, Gordon S, Silverstein SJ, Crum CP. Histological correlates of clinically occult human papillomavirus infection of the uterine cervix. Am F Surg Pathol 1988;12:198-204.

17 Tidy JA, Parry GCN, Ward P, Coleman DV, Peto J, Malcolm ADB, et al. High rate of human papillomavirus type 16 infection in cytologically normal smears. Lancet 1989;i:434.

18 Human papillomaviruses and the polymerase chain reaction [editorial]. Lancet 1989;ii:1051-2.

19 Kitchener HC. Commentary: Does HPV cause cervical cancer? Br $\mathcal{f}$ Obstet

Gynaecol 1988;95:1089-91.
20 Kitchener HC. Genital virus infection and cervical neoplasia. Br $\mathcal{F}$ Obstet Gynaecol 1988;95:182-91.

21 Singer A, Jenkins D. Viruses and cervical cancer. BMF 1991;302:251-2.

22 Evans DMD, Hudson EA, Brown CL, Boddington MM, Hughes HE, Mackenzie EFD. Management of women with abnormal cervical smears: supplement to terminology in gynaecological cytopathology. 7 Clin Pathol 1987;40:530-1

23 Pairwuti S. False-negative Papanicolaou smears from women with cancerous and precancerous lesions of the uterine cervix. Acta Cytol 1991;35:40-6.

24 Kristensen GB, Skyggebjerg K, Holund B, Holm K, Hansen MK. Analysis of cervical smears obtained within three years of the diagnosis of invasive cervical cancer. Acta Cytol 1991;35:47-50.

(Accepted 24 February 1992) 